\title{
Short communication: Effects of the progesterone receptor variants on fertility traits in cattle
}

\author{
A. M. Driver, W. Huang, S. Gajic, R. L. Monson, G. J. M. Rosa, and H. Khatib ${ }^{\mathbf{1}}$ \\ Department of Dairy Science, University of Wisconsin-Madison, Madison 53706
}

\begin{abstract}
The progesterone receptor $(P G R)$ gene is a key factor in the initiation and maintenance of pregnancy and in embryo development. Currently, it is unknown what variants of the $P G R$ gene are related to fertility traits in cattle. Identification of such variants would allow the implementation of marker-assisted selection in breeding schemes. The objective of this study was to investigate the association of single nucleotide polymorphisms (SNP) of $P G R$ with fertility traits in Holstein dairy cattle. An in vitro fertilization system was used to maximize the efficiency of the identification of genetic factors affecting fertility. This in vitro fertilization system would allow the assessment of fertilization and embryonic survival rates independently of influences from the uterine environment. A total of 5,566 fertilization attempts were performed, and a total of 3,679 embryos were produced using oocytes from 324 Holstein cows and semen from 10 Holstein bulls. Sequencing of pooled DNA samples from ovaries revealed an SNP (G/C) in intron 3 of $P G R$. A generalized linear model was used to analyze the association of this SNP with fertilization and embryonic survival rates for each ovary. Oocytes obtained from CC ovaries showed a $61 \%$ fertilization rate, compared with 68 and $69 \%$ for GC and GG ovaries, respectively. The survival rate of embryos produced from GG ovaries was 5 and $6 \%$ higher than that of GC and CC ovaries. These results indicate that the PGR SNP could be used in marker-assisted selection breeding programs in Holstein dairy cattle.
\end{abstract}

Key words: progesterone receptor, fertility, polymorphism, dairy cow

Fertility of the modern high-producing dairy cow has been decreasing for the last 30 to $50 \mathrm{yr}$ and has become a major concern of farmers and to the dairy industry worldwide (Royal et al., 2000; Dobson et al., 2007,2008 ). Previous studies have shown that a major subcomponent of infertility and higher incidence of late

Received January 5, 2009.

Accepted April 27, 2009.

${ }^{1}$ Corresponding author: hkhatib@wisc.edu embryo mortality in dairy cattle is abnormal hormone activity, causing different effects ranging from prolonged luteal activity to delayed ovulation (Lamming and Darwash 1998). However, recent studies have shown that low fertilization rates and embryonic loss - referring to death of embryos from fertilization to the completion of differentiation - seem to be the main factors contributing to infertility in dairy cattle (Santos et al., 2004; Morris and Diskin, 2008). Although genetic factors are known to be involved in this decline of fertility (Royal et al., 2002), the discovery of specific genes has been challenging (Veerkamp and Beerda, 2007). The identification of genes with major effects on fertility would allow the implementation of gene-assisted selection to improve reproductive performance in dairy cows. In previous studies, we reported associations between the genotypes of ovaries and subsequent fertility data on their oocytes and embryos for the signal transducer and activator of transcription 5A (STAT5A) and the fibroblast growth factor $2(\boldsymbol{F G F 2})$ genes with fertility traits by using an in vitro fertilization (IVF) experimental population (Khatib et al., 2008a,b). The genes FGF2 and STAT5A were chosen as candidate genes because they are members of the interferon- $\tau$ and placental lactogen pathways, which are known to be involved in the initiation and maintenance of pregnancy in ruminants (Spencer and Bazer, 2002).

Progesterone is a required hormone for pregnancy initiation, implantation, and embryo development, which are mediated by the progesterone receptor $(\boldsymbol{P G R})$ gene in mammals (McNeill et al., 2006). Indeed, several studies have shown that high as well as low concentrations of progesterone are associated with low embryonic survival (reviewed in Morris and Diskin, 2008). Mann et al. (1999, 2006) reported that successful embryo development is contingent on sufficient levels of progesterone and that a late or poor increase in progesterone levels during the luteal phase results in poorly developed embryos that are virtually incapable of secreting sufficient amounts of interferon- $\tau$ at a critical point of development.

Several research groups have questioned whether $P G R$ affects embryonic development and survival through direct action on embryos or through indirect 
Table 1. Number ${ }^{1}$ of ovaries and oocytes used in fertilization, and mean number of oocytes and embryos per ovary and standard deviation

\begin{tabular}{lccccc}
\hline Bull & No. of ovaries & No. of oocytes & Oocytes/ovary (SD) & No. of embryos & Embryos/ovary (SD) \\
\hline 1 & 94 & 1,259 & $13.4(8.94)$ & 842 & $9.0(6.89)$ \\
2 & 58 & 606 & $10.4(7.74)$ & 428 & 179 \\
3 & 20 & 330 & $16.5(7.04)$ & 121 & $9.0(4.35)$ \\
4 & 20 & 263 & $13.2(8.54)$ & 349 & $6.1(4.37)$ \\
5 & 40 & 543 & $13.6(7.49)$ & 417 & $8.7(6.37)$ \\
6 & 67 & 568 & $8.5(5.05)$ & 430 & $6.2(4.13)$ \\
7 & 67 & 744 & $10.9(7.46)$ & 517 & $7.4(4.10)$ \\
8 & 68 & 1,343 & $15.1(10.76)$ & 905 & $8.74)$ \\
10 & 89 & 1,196 & $18.1(15.80)$ & 849 & $10.2(7.88)$ \\
\hline
\end{tabular}

${ }^{1}$ Numbers include all ovaries collected and all embryos produced.

effects of maternal factors produced in the reproductive tract (Hou and Gorski, 1993; Ying et al., 2000; Morris and Diskin, 2008). To affect fertilization rate, $P G R$ must be expressed in sperm, oocytes, or both. Gene expression and immunocytochemistry analyses have shown the presence of $P G R$ in oocytes and in 2-cell and 4-cell stages of pig embryos, but it was undetectable in developmental stages after the 4-cell stage (Ying et al., 2000). In addition, expression analysis of $P G R$ in cumulus cells surrounding mature human oocytes revealed an important role of this gene in the regulation of oocyte maturation and embryo development (Hasegawa et al., 2005). Moreover, in a recent study, Buser et al. (2007) reported that after $P G R$ is activated in response to progesterone, it translocates to the nucleus, where it binds the $\beta$-CN promoter. The authors found that a mutual interference between $P G R$ and $S T A T 5 A$ at the $\beta$-CN promoter has an important role in the repression of $\beta-\mathrm{CN}$ transcription during pregnancy. Given that $S T A T 5 A$ has been found to affect fertilization rate and early embryonic survival and that $P G R$ is key gene in pregnancy and embryonic development, $P G R$ was chosen as a candidate gene for its potential effects on fertility traits in cattle. The objective of this study was to investigate the association of the $P G R$ gene variants with fertilization rate and early embryonic survival.

In previous studies, we reported the construction of an IVF system in cattle that enables us to detect associations between polymorphisms in candidate genes and fertility traits (Khatib et al., 2008a,b). We assessed the degree of association between $P G R$ and fertilization and embryo survival traits by using a total of 5,566 fertilization attempts and a total of 3,679 embryos produced using oocytes from 324 Holstein cows and semen from 10 Holstein bulls as described in Khatib et al. (2008a,b). Briefly, all oocytes that were aspirated from an ovary were combined with semen from 1 bull for an incubation period of 18 to $25 \mathrm{~h}$. Ovaries from which fewer than 4 oocytes were harvested were excluded from the analysis. A summary of the experimental design, including the number of ovaries and oocytes used in the fertilization and the average number of oocytes and embryos per ovary for each sire, is reported in Table 1. Fertilization rate was calculated as the number of cleaved embryos at $48 \mathrm{~h}$ postfertilization out of the total number of oocytes exposed to sperm. After the fertilization period, putative zygotes were stripped of their cumulus cells by vortexing and cultured until d 7. Survival rate of the embryos was calculated as the number of blastocysts on $\mathrm{d} 7$ of development out of the total number of embryos cultured.

Deoxyribonucleic acid was extracted from ovaries and semen samples using phenol-chloroform standard protocols. To detect SNP in $P G R, 3$ pooled ovary DNA samples were amplified using different pairs of primers. Amplification and SNP identification were as described in Khatib et al. (2008a,b). One C/G SNP was detected in the ovaries at position 59752 in intron 3 of $P G R$ (GenBank accession no. NC_007313, region 6406286 to 6522574). For genotyping of ovaries, the primers PGRF4 5'-GTGAATTTGCTCCAAGATTC-3' and PGRR4 5'-GCCCGACCTTCCCATAAC-3' were used to amplify an 869-bp fragment. The PCR products were digested with the restriction enzyme AdeI and electrophoresed on a 2.0\% agarose gel.

Association of $P G R$ variants in ovaries with fertilization and survival rates was analyzed using a generalized linear model methodology (McCullagh and Nelder, 1989) for binary outcomes, using the following logistic regression model:

$$
\begin{gathered}
\log \left(\frac{p_{i}}{1-p_{i}}\right)=\mu+\text { Bull }_{(i)}+\operatorname{STAT5A}_{(i)} \\
+ \text { FGF2 }_{(i)}+P G R_{(i)},
\end{gathered}
$$

where $p_{i}$ is the survival rate of embryos produced from the $i$ th ovary $(i=1,2, \ldots \mathrm{n})$, which has been fertilized with semen from $\operatorname{Bull}_{(i)}$ (10 different bulls were used), and which has the genotypes $S T A T 5 A_{(i)}$ for a $S T A T 5 A$ 
Table 2. Number of fertilization attempts and embryos of each genotypic class, observed fertilization rate (FR) and embryonic survival rate $(\mathrm{SR})$, and the association test between progesterone receptor $(P G R)$ gene variants and fertility traits

\begin{tabular}{|c|c|c|c|c|c|}
\hline Ovary genotype & No. of ovaries ${ }^{1}$ & No. of fertilizations & Observed FR & No. of embryos & Observed SR \\
\hline $\mathrm{GC}$ & 155 & 2,721 & 0.68 & 1,832 & 0.31 \\
\hline Association test ( $P$-value $)$ & & & 0.00039 & & 0.00036 \\
\hline
\end{tabular}

${ }^{1}$ Numbers successfully genotyped and having more than 4 oocytes per fertilization.

SNP (Khatib et al., 2008b), FGF2 ${ }_{(i)}$ for an FGF2 SNP (Khatib et al., 2008a), and $P G R_{(i)}$ for the $P G R$ SNP in this study; STAT5A and FGF2 are included in the model because they showed a significant association with survival rate (Khatib et al., 2008a,b). Similarly, fertilization rate was modeled with STAT5A and PGR, but not FGF2, because it was not significant (Khatib et al., 2008a) for this trait. A likelihood ratio test was applied to assess the significance of the PGR SNP effect in the model. The analysis was performed using $\mathrm{R}$ with functions from the base packages ( $\mathrm{R}$ Development Core Team, 2008). The GG, GC, and CC genotypic frequencies in ovaries were $0.37,0.48$, and 0.15 , respectively, and frequencies of alleles $\mathrm{G}$ and $\mathrm{C}$ were 0.61 and 0.39 , respectively. The fertilization rate of oocytes from CC ovaries was $61 \%$, compared with 68 and $69 \%$, those obtained from GC and GG ovaries, respectively $(P=0.00039$; Table 2). Because the oocytes cannot be used for DNA extraction and genotyping (because they are needed for the IVF process), the ovaries from which these oocytes were collected must be genotyped. Associations between genotypes of ovaries for $P G R$ and fertilization and survival rates were then performed. Thus, genotypes of ovaries represent genotypes of oocytes used in the fertilization process. Furthermore, it has been determined that the early stages of mammalian development are dependent on transcripts and proteins present in the oocytes (Zuccotti et al., 2008), thus making the female gamete important in the current study.

The survival rate of embryos produced from GG ovaries was $36 \%$, compared with 31 and $30 \%$ produced from GC and $\mathrm{CC}$ ovaries $(P=0.00034)$, respectively (Table 2). Hou and Gorski (1993) reported the expression of $P G R$ in mouse embryos at the blastocyst stage. The authors concluded that progesterone and $P G R$ are both crucial for embryonic survival. Thus, our results on the association of $P G R$ with fertilization and survival rates of embryos support the hypothesis of Hou and Gorski (1993) that PGR acts directly in embryos and that it may have a significant impact on early embryonic development.
One limitation in this study is the lack of pedigree information because ovaries were collected from a slaughterhouse. Nevertheless, because of the large number of farms represented in the slaughterhouse and the length of collection time (approximately $3 \mathrm{yr}$ ), we assumed that cows were not related. A second limitation in this study is the relatively small number of ovaries examined, which in turn could increase the chance of false positive associations. Given that the GG genotype was found to be associated with both fertilization and survival rates, $P G R$ could be used in gene-assisted selection breeding programs in dairy cattle to improve fertility.

\section{ACKNOWLEDGMENTS}

This study was supported by The Draper Technology Innovation Fund from the Graduate School, University of Wisconsin-Madison, and by Igenity Livestock Production Business Unit, Merial Ltd. (Duluth, GA).

\section{REFERENCES}

Buser, A. C., E. K. Gass-Handel, S. L. Wyszomierski, W. Doppler, S A. Leonhardt, J. Schaack, J. M. Rosen, H. Watkin, S. M. Anderson, and D. P. Edwards. 2007. Progesterone receptor repression of prolactin/signal transducer and activator of transcription 5 -mediated transcription of the beta-casein gene in mammary epithelial cells. Mol. Endocrinol. 21:106-125.

Dobson, H., R. Smith, M. Royal, Ch. Knight, and I. Sheldon. 2007. The high- producing dairy cow and its reproductive performance. Reprod. Domest. Anim. 42(Suppl. 2):17-23.

Dobson, H., S. L. Walker, M. J. Morris, J. E. Routly, and R. F. Smith. 2008. Why is it getting more difficult to successfully artificially inseminate dairy cows? Animal 2:1104-1111.

Hasegawa, J., A. Yanaihara, S. Iwasaki, Y. Otsuka, M. Negishi, T. Akahane, and T. Okai. 2005. Reduction of progesterone receptor expression in human cumulus cells at the time of oocyte collection during IVF is associated with good embryo quality. Hum. Reprod. 20:2194-2200.

Hou, Q., and J. Gorski. 1993. Estrogen receptor and progesterone receptor genes are expressed differentially in mouse embryos during preimplantation development. Proc. Natl. Acad. Sci. USA 90:9460-9464.

Khatib, H., C. Maltecca, R. L. Monson, V. Schutzkus, X. Wang, and J. J. Rutledge. 2008a. The fibroblast growth factor 2 gene is associated with embryonic mortality in cattle. J. Anim. Sci. 86:2063-2067.

Khatib, H., R. L. Monson, V. Schutzkus, D. M. Kohl, G. J. M. Rosa, and J. J. Rutledge. 2008b. Mutations in the STAT5A gene are 
associated with embryonic survival and milk composition in cattle. J. Dairy Sci. 91:784-793.

Lamming, G. E., and A. O. Darwash. 1998. The use of milk progesterone profiles to characterise components of subfertility in milked dairy cows. Anim. Reprod. Sci. 52:175-190.

Mann, G. E., M. D. Fray, and G. E. Lamming. 2006. Effects of time of progesterone supplementation on embryo development and interferon-tau production in the cow. Vet. J. 171:500-503.

Mann, G. E., G. E. Lamming, R. S. Robsinson, and D. C. Wathes. 1999. The regulation of interferon-tau production and uterine hormone receptors during early pregnancy. J. Reprod. Fertil. Suppl. 54:317-328.

McCullagh, P., and J. A. Nelder. 1989. Generalized Linear Models. 2nd ed. Chapman and Hall, London, UK.

McNeill, R. E., J. M. Sreenan, M. G. Diskin, M. T. Cairns, R. Fitzpatrick, T. J. Smith, and D. G. Morris. 2006. Effect of systemic progesterone concentration on the expression of progesteroneresponsive genes in the bovine endometrium during the early luteal phase. Reprod. Fertil. Dev. 18:573-583.

Morris, D., and M. Diskin. 2008. Effect of progesterone on embryo survival. Animal 2:1112-1119.

R Development Core Team. 2008. R: A Language and Environment for Statistical Computing. R Foundation for Statistical Computing, Vienna, Austria.
Royal, M., G. E. Mann, and A. P. Flint. 2000. Strategies for reversing the trend towards subfertility in dairy cattle. Vet. J. 160:53-60.

Royal, M. D., J. E. Pryce, J. A. Woolliams, and A. P. Flint. 2002. The genetic relationship between commencement of luteal activity and calving interval, body condition score, production, and linear type traits in Holstein-Friesian dairy cattle. J. Dairy Sci. 85:30713080.

Santos, J. E. P., W. W. Thatcher, R. C. Chebel, R. L. A. Cerri, and K. N. Galvão. 2004. The effect of embryonic death rates in cattle on the efficacy of estrus synchronization programs. Anim. Reprod. Sci. 82-83:513-535.

Spencer, T. E., and F. W. Bazer. 2002. Biology of progesterone action during pregnancy recognition and maintenance of pregnancy. Front. Biosci. 7:d1879-d1898.

Veerkamp, R. F., and B. Beerda. 2007. Genetics and genomics to improve fertility in high producing dairy cows. Theriogenology 68(Suppl. 1):S266-S273.

Ying, C., Y. C. Yang, W. F. Hong, W. T. Cheng, and W. L. Hsu. 2000. Progesterone receptor gene expression in preimplantation pig embryos. Eur. J. Endocrinol. 143:697-703.

Zuccotti, M., V. Merico, L. Sacchi, M. Bellone, T. C. Brink, R. Bellazzi, M. Stephanelli, C. A. Redi, S. Garagna, and J. Adjaye. 2008. Maternal Oct-4 is a potential key regulator of the developmental competence of mouse oocytes. BMC Dev. Biol. 8:97. 